Harding, E. K., Crone, E. E., Elderd, B. D., Hoekstra, J. M., McKerrow, A. J., Perrine, J. D., Regetz, J., Rissler, L. J., Stanley, A. G., Walters, E. L. and Group, N. H. C. P. W. (2001), The Scientific Foundations of Habitat Conservation Plans: a Quantitative Assessment. Conservation Biology, 15: 488-500. doi: 10.1046/j.1523-1739.2001.015002488.x

\title{
The Scientific Foundations of Habitat Conservation Plans: a Quantitative Assessment
}

Elaine K. Harding, Elizabeth E. Crone, Bret D. Elderd, Jonathan M. Hoekstra, Alexa J. McKerrow, John D. Perrine, Jim Regetz, Leslie J. Rissler, Amanda G. Stanley, Eric L. Walters, and Nceas Habitat Conservation Plan Working Group

Abstract: The number of habitat conservation plans (HCP) has risen dramatically since the first plan was written over 18 years ago. Until recently, no studies have quantitatively investigated the scientific foundations underlying these documents. As part of a larger study of HCPs, we examined 43 plans primarily to assess the availability and use of scientific data and secondarily to determine the extent of involvement by, and influence of, independent scientists within the process. Specifically, our analysis focused on five key steps taken when an HCP is developed: assessing status of a species, determining take, predicting the project effects, mitigating for those effects, and monitoring of take and mitigation. In general, we found that the preparers of HCPs utilized existing scientific information fairly well, with $60 \%$ of plans not missing any available information described by our study as "starkly necessary." The most common types of underutilized available data included those describing the influence of stochastic processes and habitat quality or quantity on species persistence. For many species, however, data on biology or status simply did not exist, as demonstrated by the fact that we could locate quantitative population estimates for only $10 \%$ of the species. Furthermore, for $42 \%$ of the species examined we had insufficient data and analysis to determine clearly how predicted take might affect the population. In many cases, mitigation measures proposed to offset take frequently addressed the most important local threats to the species with moderately reliable strategies. Species with monitoring programs rated as sufficient had plans that proposed to collect a greater amount of "quantitative" data than did those programs rated insufficient. Finally, when species "experts” were consulted, plan quality was generally higher. Overall, available scientific information in a majority of categories was fairly well utilized, but for many species additional studies and more in-depth analyses were required to provide adequate support for issuance of an incidental take permit.

Las Bases Científicas de los Planes de Conservación del Hábitat: una Evaluación Cuantitativa

Resumen: El número de planes de conservación del hábitat (PCH) se ha incrementado dramáticamente desde que el primer plan fue escrito hace más de 16 arlos. Hasta hace poco, no existían estudios que investigaran cuantitativamente los fundamentos cientificos básicos de estos documentos. Como parte de un gran estudio sobre los PCHs, investigamos 43 planes, principalmente para evaluar la disponibilidad y uso de datos cientificos y además para determinar el grado de participacidn, y la influencia de, cientificos independientes dentro del proceso. Especificamente, nuestro análisis se enfoca en cinco pasos clave llevados a cabo durante el desarrollo de un PCH: la evaluacidn de estatus de una especie, la 
determinacidn de cosecba, la prediccidn de los efectos del proyecto, la mitigacidn de estos efectos y el monitoreo de la cosecba y la mitigacidn. En general, los elaboradores de PCHs utilizaron informacidn cientifica bastante bien, con $60 \%$ de los planes sin carecer de ninguna informacidn viable descrita por nuestro estudio como "rigurosamente necesaria." Los tipos más comunes de datos disponibles poco utilizados incluyeron a aquellos que describian la influencia de procesos estocásticos y de la calidad o cantidad del bábitat en la persistencia de especies. Sin embargo, para mucbas especies, los datos sobre su biologia o estatus simplemente no existen, a como se ba demostrado por el becbo de que solo podiamos localizar estimaciones poblacionales cuantitativas para $10 \%$ de las especies. Mas aún, $42 \%$ de las especies examinadas tuvo datos y análisis insuficientes como para que nuestros revisores pudieran determinar claramente el como la cosecba estimada pudiera afectar a la poblacidn. En mucbos casos las medidas de mitigacidn propuestas para contrarrestar la cosecba frecuentemente toma en consideracidn las amenazas locales más importantes para las especies con estrategias relativamente moderadas. Las especies con programas de monitoreo estimados como suficientes tuvieron planes que proponian colectar una mayor cantidad de datos "cuantitativos" que aquellos programas que fueron estimados como insuficientes. Finalmente, cuando se consultd a "expertos" en especies, la calidad del plan fue en general mayor. En general, la informacidn cientifica disponible en la mayoria de las categorias fue bastante bien utilizada, pero para mucbas especies se requirid de estudios adicionales y de análisis de mayor profundidad para apoyar adecuadamente la emisidn de un permiso de cosecba incidental.

\section{Introduction}

In 1983 the first habitat conservation plan (HCP) was approved for San Bruno Mountain near San Francisco, California. This plan established measures to protect and maintain the endangered Mission blue butterfly (Icaricia icarioides missionensis) and other endemic species, while enabling private landowners to proceed with their development plans (San Bruno Mountain Habitat Conservation Plan 1982). With this plan often being cited as a model (Hood 1998), HCPs have since been advanced as a politically viable method for resolving potential conflicts between private development and endangered species protection in the United States (Bean \& Wilcove 1997). Once an HCP is approved, an incidental take permit is issued to the project applicant, allowing them to legally take a designated number of individuals of a federally listed species ( U.S. Endangered Species Act [ESA], Section 9: definition of take is to "harass, harm, pursue, hunt, shoot, wound, kill, trap, capture or collect. . .or attempt to engage in any such conduct. . .or [cause] indirect harm through modification of habitat").

In the last several years, the U. S. Fish and Wildlife Service (USFWS) has promoted the development of HCPs with active support from the Secretary of the Interior. Consequently, the number of approved HCPs increased from only 14 plans in 1992 to 225 by December 1997. 
Currently, most HCPs address effects on a single species in an area of $<100$ ha, but the number of large, multi-species and habitat-based plans is increasing (Kareiva et al. 1998). As additional populations of endangered (and candidate) species are included in the HCP process, it is important to evaluate how effectively science is used within these plans to ensure the long-term viability of these species (Kaiser 1997). Recognizing this, the American Institute of Biological Sciences (AIBS) and the National Center for Ecological Analysis and Synthesis (NCEAS) sponsored a study to review the nature and quality of science in HCPs by using a large, standardized data set (Kareiva et al. 1998).

Although both HCP proponents and critics agree that these plans should be based on a strong foundation of scientific data and ecological principles (Noss et al. 1997; USFWS \& NMFS 1994, 1999), there exists considerable ambiguity regarding the nature of the information necessary for a scientifically credible document. At issue is the question of whether the "best available" science, a term used in USFWS policy documents, is actually used in HCPs. Previous reviews of HCPs report that many fail to make use of the best available science (Noss et al. 1997; Hood 1998; D. Murphy et al. unpublished data). These studies, however, were based on case-study assessments rather than systematic analyses of a broad spectrum of plans. Also, it may be that the most current scientific data may not constitute the "best" data for developing a solid conservation strategy. We attempt to address these issues by quantitatively evaluating the availability and use of scientific information in habitat conservation planning over a large sample of representative plans.

We utilized data collected by the AIBS and NCEAS study to address three principal questions about the use of science in HCPs. First, we examined how well available scientific data and information were used during HCP development. Second, we evaluated whether the conclusions in these documents were supported by the scientific literature and whether the types of data proposed for collection during monitoring were relevant. Finally, we investigated the extent to which involvement of independent scientists and science advisory boards during plan development influenced the scientific quality of HCPs. Our focus was only on how science was used in HCPs; we did not attempt to assess how these documents balanced biological and economic concerns or how well they adhered to the legal requirements defined in the ESA and its implementing regulations.

\section{Methods}

A motivating goal of the AIBS and NCEAS project was to conduct a quantitative analysis of the scientific information available during the development of HCPs and to assess how that information was incorporated into the plans. To achieve this goal, we selected 43 of the 227 HCPs approved as of December 1997 to represent the range of HCPs by size, geographic location, subject taxa, and year of approval. Our subset included more than $80 \%$ of the listed species affected by HCPs and 14 of the most common species (Table 1).

We used a detailed questionnaire of 965 questions to review each HCP. The first 176 questions, referred to as plan questions, solicited data on attributes of the plan itself, such as year approved, number of species covered, and number and affiliations of individuals on steering committees or science advisory boards. A second series of 789 questions, or species questions, examined the content and quality of scientific information pertaining to each of the primary listed species 
covered by the plan. The species questions were organized around five stages of the habitat conservation planning process: (1) assessment of the current status of the species (status),

(2) estimation of the anticipated incidental take (take), (3) evaluation of how take would affect the species (impact), (4) measures proposed to minimize and mitigate the effect of take (mitigation), and (5) monitoring protocols for assessing the amount of take and effectiveness of mitigation measures (monitoring). For the species questions, reviewers recorded detailed data on what specific types of scientific information were and were not available to HCP developers and to what extent such information was used in HCPs. Reviewers were essentially asked to use their collective professional judgement on many questions dealing with the use of data in each section.

Intensive reviews of the 43 HCPs were conducted by a working group of 110 researchers from eight universities, which included faculty members, postdoctoral fel lows, and graduate students (Savage 1998). During the fall of 1997, the working group members participated in concurrent seminars at their resident institutions, among which the 43 HCPs were divided for review. In these seminars, researchers reviewed the assigned HCPs and the associated incidental take permits, USFWS biological opinions on the permits, and environmental impact reports. Researchers also conducted literature searches for biological information about each covered species. In all, researchers logged approximately 16,000 person-hours and generated a database of 89,903 entries.

To assess any potential bias in these answers, all working groups answered a subset of questions from the larger questionnaire, including subjective ones, for a selected number of HCPs. These assessments were compared across the groups to ensure that the respective judgements were generally unbiased. Because no strong differences in any ratings were found, and because a set of summary "quality" ratings assigned at the end of each section corresponded well with the set of prior detailed questions (see Kareiva et al. 1998), we also used these subjective “quality” ratings to address questions about general scientific quality (see following section on scientific quality and involvement of scientists).

The main report on the project was released by AIBS in December 1998 (Kareiva et al. 1998). This report contains detailed descriptions of the project and data, including a list of the HCPs reviewed, how they were selected, the list of plan and species questions, and general results and recommendations (the AIBS report, along with the dataset, are available online at http://www.nceas.ucsb.edu/ projects/hcp).

\section{Analytical Methods}

Because of the large number of questions asked in this study, we used only a small subset for the analysis. Specifically, we used those questions that addressed the types of data found across many plans, namely those dealing with population and habitat measures or those broadly applicable to many types of plans. To assess the use of science across all species in these plans, we used either species or plan questions as our unit of analysis. The maximum sample size was 97 for species questions and 43 for plan questions, although the sample size for each analysis was often smaller because of questions being unanswerable or not applicable or was larger if samples across plans were combined (Kareiva et al. 1998). Because 14 of the plans dealt with multiple species, we could not assume independence of each species, so any analysis by species was potentially confounded by the influence of a plan. To correct for this bias in species question data, we (1) summarized the data by plan, (2) used partial correlation analysis, or (3) analyzed the data both with and without the multispecies plans. [Table 1]

\section{AVAILABLE DATA, USE, AND ANALYSIS}


To evaluate how scientific information was incorporated into the HCPs, we examined data available to the plan preparers. For each species we searched the scientific literature for information on basic biology, range-wide trends in abundance, and quantity of available habitat which was published prior to the plan's completion. We recorded whether the data were estimated quantitatively or qualitatively (e.g., populations declining, but no estimate of rate).

We also determined if, and how, the available scientific information was used within the documents. First, we calculated the percentage of species for which little or no available data was missing for two categories, population and habitat data. This information is most often relevant for assessing a species' status and determining the net effects of a project. Next, we calculated the number of plans in which at least one species was rated in each of four categories from "nothing significant missing" to "starkly necessary information missing" across all categories of data in each section of the HCP. Further, for those plans where available information would have altered the outcome of assessments at least "qualitatively," we totaled the number of plans for each of nine broad categories of data (e.g., population numbers, metapopulations, genetics) within each section.

To understand the general types of analysis used in HCPs, we rated the types of analytical approaches used on a scale from predictive models (such as population viability analysis), to subjective, qualitative opinions of plan preparers (Kareiva et al. 1998). Because different kinds of information may be necessary for assessing each species, we decided to represent the quality of all sec tions by tallying the nature of the best analysis used across all sections. Our scoring of "best" was within a range that ranked quantitative data and analysis more highly than "expert opinion” or "qualitative" data. To avoid overweighting large-scale plans with many species, we tallied the number of plans in which at least one species was used for that analysis in the plan (i.e., if one species used "quantitative" analysis and the other four species in that plan did not, then that plan was counted in the quantitative analysis category for that section of the document).

\section{TAKE, IMPACTS, AND MITIGATION ASSESSMENT}

We performed several analyses to identify trends in how plan preparers made assessments in HCPs. Because calculating take is an important cornerstone of any HCP, we first determined the proportion of plans in which the amount of take was quantified as either number of individuals or percentage of the population. Then, to clarify whether HCP preparers were clearly identifying the species-specific effects most critical to the population in the HCP area, we assessed whether the literature supported the preparer's rankings of the plan's effects. To address this question, we used partial correlation analysis (1) to determine whether the plan itself influenced this relationship and (2) to assess the relationship between these rankings after plan effects were removed. Finally, we describe the primary categories of available but unused information that could have, at least qualitatively, changed the conclusions in the impact section.

To understand whether mitigation strategies were clearly justified, we determined whether the most important local threats to each species were addressed by the proposed mitigation measures by comparing the proportion of species in each category across three sections: (1) local threats, (2) stated project effects, and (3) proposed mitigation strategies. Category names within each section varied from "habitat loss" in the local threats category to "habitat restoration" in the mitigation strategies category. Because the use of a mitigation measure should be based primarily on its likelihood of addressing the specific effect and secondarily on its reliability, we analyzed the relationship between the use and reliability of each mitigation technique. By reliability we mean how well the effectiveness of a mitigation measure had been demonstrated and documented by the literature (rated 0 to 3: 0 , none; 3, proven to work). By use we mean the degree to which an 
HCP depended on a particular mitigation technique to counter the anticipated effects (rated 0 to 3 : 0 , none; 3 , major use in plan). We used chi-square analysis to assess the overall relationship between reliability and use for all categories of mitigation combined (e.g., avoidance, habitat preservation) over all species and excluding multispecies plans.

\section{MONITORING PROGRAM}

We asked whether the sufficiency of a monitoring program's ability to determine take levels or mitigation success was influenced by the type of data proposed for collection. The data were rated on a 0 to 5 scale: 0 , not collected; 1 , expert opinion; 2, qualitative; 3 , quantitative with limited and/or poor statistical analysis; 4, quantitative with clear and relevant analysis; 5 , quantitative with good modeling. We used chi-square analysis to compare the type of data collected for species answering yes (sufficient) with those answering no (insufficient) for both take and mitigation monitoring. This analysis was done for two main categories of information: population size and habitat amount (1) across all species and (2) excluding species in multispecies plans.

If plans were weak when take was predicted, we then hypothesized that these same plans would have been improved by implementing a well-designed monitoring program that could more accurately determine the actual take. To test this hypothesis, we compared the number of species with sufficient or insufficient estimates of take with those having a sufficient or insufficient monitoring of take, as described in the HCP, by means of a chi-square test over all species and then excluding multi-species plans.

\section{Scientific Quality and Involvement of Scientists}

\section{QUALITY SCORES}

At the end of each section in our species questionnaire, we evaluated the overall adequacy of that part of the assessment (status, take, impact, mitigation, monitoring) based on a subjective scale from 1 to 6 (1, excellent; 2, above average; 3 , sufficient; 4 , significantly lacking; 5 , inadequate; 6 , extremely poor). As described earlier, these ratings correlated well with the prior detailed quantitative questions addressed in that section. Using these summary ratings, we asked the following questions: (1) Are the data analyses in some sections of the HCPs consistently better than others? (2) How consistent is the quality of a given HCP across all sections? (3) What is the distribution of the "average" scientific quality of data and analyses in HCPs, averaged over all species and sections covered by the HCP?

To address the first question, we assessed the percentage of species across plans that were rated as "sufficient" or better in each category. In answering the second, we used pairwise Spearman rank correlations of the scores in each section for each species over all HCPs. We addressed the third question in two ways. First, without weighting the importance of each step of analysis (e.g., status, take), we ranked plans by the score for the worst section in each plan and then divided the plans into two types based on the approximate break of a median score between 4 (significantly lacking) and 5 (inadequate). The two categories were thus above and below our median score: (1) plans having no sections rated "inadequate" or worse, and (2) plans having at least one section rated "inadequate" or worse. The second approach to addressing overall quality was to determine the proportion of plans with a total score, summed over the 5 sections and averaged over all species in a plan, of less than 20 - in other words, rated better than "significantly lacking" (the total ranges from 5, excellent, to 30, extremely poor). 


\section{INVOLVEMENT OF SCIENTISTS}

To assess whether the involvement of scientists was related to our measure of quality across plans, we used two measures. We compared the "average" quality of plans with and without science advisory boards, and we contrasted the quality of plans that did or did not consult scientists recognized as species "experts." For each measure, we divided plans into the two categories described above (using the median score break) and tested the association of scientist involvement with plan quality using chi-square analysis.

\section{Results \\ Availability and Use of Scientific Information AVAILABLE DATA, USE, AND ANALYSIS}

We found a striking lack of information on the basic biology of many species for which take permits had been given (Table 2). Clutch or litter size was known for only $67 \%$ of species, lifespan for $46 \%$, and lifetime reproductive output of individuals for $19 \%$. There were five species (7\%) for which none of these aspects of life history was known when incidental take permits were given. Population trends, either local or regional, had been quantitatively estimated for $<10 \%$ of species covered by HCPs. For $51 \%$ of species, no information was available on longterm local population trends, with 78\% unable to provide a quantitative estimate of population change (lambda). Most of the remaining species could be qualitatively classified as stable, declining, or increasing (Fig. 1). The less well-known species ranged from recently discovered cavedwelling invertebrates in Texas to the intensively studied but poorly understood Marbled Murrelet (Brachyramphus marmoratus) in the Pacific Northwest. [Table 2] [Table 3]

In general, our subset of HCPs showed that preparers used existing data and supporting literature quite well, as demonstrated by the high percentage of species-specific assessments with little or no information missing from the HCP for the four most relevant categories of data (Table 3).

Furthermore, $60 \%$ of the plans had no "starkly necessary" available information missing across all sections and categories of data, for all species covered by the HCP (Table 4). A large number of plans (75\%), however, did not cite some data that could have altered the assessment at least qualitatively, but not strongly, in at least one section of the plan. On a section-by-section basis, relevant information was missing from assessments of status and mitigation more often than take and impact (chi-square $=17.5, n=43, p<0.05$ ) (Table 4). Yet, data that would have changed the conclusions in these assessments "qualitatively," or more strongly, were found in greater proportion within the impacts or mitigation steps. So, although many species assessments did not overlook literature relevant to predicting effects, this available but unused information was often deemed important to the scientific conclusions. Specifically, information describing how stochastic processes influenced a species and data relating habitat quantity and quality to species persistence were of moderate or higher importance to the assessment but were underused (Table 5). 
In addition, few HCPs were based only on opinion, without any quantitative data or analysis. In fact, plans used process-oriented modeling (e.g., population viabil ity analysis) more often than they based their assessments on expert opinion across all sections of the plans (Table 6). Patterns of data and analysis quality were consistent across sections, with two exceptions. Analysis of mitigation was most variable in quality, and process-oriented modeling was used least often to quantify take (chi-square $=21, n=97, p=0.05$ ).

\section{TAKE, IMPACTS, AND MITIGATION ASSESSMENTS}

For $42 \%$ of the species examined, data and analysis in the HCP and related documents were insufficient to clearly indicate how predicted take might affect the species. In fact, plan writers failed to quantify the predicted take in almost half of the plans (42\%), with $40 \%$ describing take in terms of the number of individuals or the percent of the population, and $18 \%$ quantifying take for some but not all of species in a plan. Our analysis showed, however, that the effects deemed important to a species at the local level, as determined by the preparers of the document, were in good agreement with the effects found to be relevant in the literature (partial correlation, $n=59$; for 10 categories, $p<0.05$ with correlation coefficients, $r>0.46$; for one category, $p>0.10$ ). For example, a majority of the HCPs listed percent habitat loss as a key factor affecting the covered species, and in our review of the ecological literature available for each species, we found this a well-justified conclusion. Also, when assessing effects on a species, preparers of HCPs underutilized one category of information: $26 \%$ of plans did not include available data on environmental stochasticity. This category includes factors such as natural or anthropogenic catastrophes, variability in the environment, succession, and natural disturbance regimes. Thus, important but complex scientific information was often not incorporated into plans for assessment of how permitted activities might affect the future viability of a species.

Habitat alteration (loss, fragmentation, and/or degradation) was the primary local threat (71\%) to a majority of species covered by HCPs and the most prominent global threat. Similarly, the primary form of take for the majority of plans was habitat loss or degradation (72\%), followed by mortality of adults or juveniles (25\%). Within our 43 plans, mitigation measures spanned a range of activities, the most common being avoidance and minimization of effects (e.g., siting the development away from inhabited lands) (33\%). Preservation of land, through habitat acquisition or conservation easement, was also commonly (22\%) used as a mitigation measure. Overall, planned mitigation measures frequently (>75\%) addressed the most important local threats to the species, as well as mitigating the specific effects of permitted activities under HCPs. For example, when local habitat loss was named as a primary threat by our reviewers, the mitigation described within the plan addressed this threat in $84 \%$ of the cases. To determine if the more scientifically tested mitigation strategies were used more frequently, we assessed trends for all types of mitigation used on a per-species basis and found a significant relationship between reliability and use ratings of those measures (all species: chi-square $=181, n=416, p<0.0001$; excluding multispecies plans: chi-square $=52, n=123, p<0.0001$ ). [Table 4] [Table 5]

\section{MONITORING PROGRAM}

The more highly ranked monitoring sections collected more quantitative data for population size for both take (all species: chi-square $=17, n=65, p<0.05$; excluding multispecies plans: chi- 
square $=12, n=16, p<0.01$ ) and mitigation (all species: chi-square $=22, n=68, p<0.0001$; excluding multispecies plans: chi-square $=7, n=13, p<0.10$ ). When collecting data on habitat amount, single species plans were less likely to show differences in sufficiency of take (all species: chi-square $=13, n=59, p<0.05$; excluding multispecies plans: chi-square $=6, n=16, p$ $=0.18$ ) and mitigation monitor-

ing (all species: chi-square $=29, n=63, p<0.0001$; excluding multispecies plans: chi-square $=$ $7, n=13, p=0.78$ ) by the type of data and analyses proposed. In addition, poorly ranked monitoring programs did not collect any data at all or used a lower proportion of statistical analysis and modeling for making assessments (Fig. 2; mitigation monitoring shown, but trends for take were similar). But plans rated sufficient also had a high proportion of species for which there were "no data collected." In line with the general trend of HCPs to be weak or strong overall, plans for species with poorly substantiated estimates of take also had less rigorous monitoring programs to document the take (all species: chi-square $=12, n=66, p<0.01$; excluding multispecies plans: chi-square $=4, n=16, p=0.05$ ). These results suggest that monitoring is not often used to provide an accurate assessment of the resulting amount of take or of the relative success of mitigation in mediating a project's effects.

\section{Scientific Quality and Involvement of Scientists}

\section{QUALITY SCORES}

Examining each step of a species assessment (e.g., status, take) separately, we found that the authors of HCPs generally used adequate science when assessing the current status of a species and estimating the expected level of take (Fig. 3). Sufficient or better information and analysis was used in the first two sections of an HCP: $64 \%$ of cases for status and 53\% for take. But HCPs were more often lacking in scientific quality when estimating future effects, namely effects on species, probable success of mitigation, and the adequacy of proposed monitoring efforts: only 35\%, 46\%, and $40 \%$ of plans rated "sufficient" or better for each assessment, respectively. The successive steps of assessment were strongly correlated for each species across plans (10 Spearman rank correlations, $p<0.10$ ), demonstrating that those plans with adequate status assessments were also rated as having logical and clear assessments of scientific quality in all other sections. As an indication of the "average" scientific quality of a plan (encompassing the five sections of each HCP) there were 18 plans with an "inadequate" or worse rating for the most poorly rated section, and 18 with no inadequate rating in any step (7 plans did not have a rating for one section and were excluded). When these trends were examined by a summed total over all sections, $56 \%$ of plans ( $n=$ 36) were rated as "significantly lacking” or worse. [Table 6] [Figure 2]

\section{INVOLVEMENT OF SCIENTISTS}

The USFWS currently does not require external scientific involvement during the development or review stages of HCPs, although non-agency scientists can be invited to be participants on either steering committees or science advisory boards, both of which are optional for the permit 
applicant. In our sample, steering committees were employed in 14 plans, although we could locate information on the composition of these committees for only 13 plans. For those plans, the average composition consisted of 37\% industry, 30\% government, $11 \%$ environmental group members, and $5 \%$ academics; $18 \%$ of committee memberships were not identified. The average size of a committee was 15, with a range of 2-29. In comparison, science advisory boards were employed for 11 of the 43 plans, with data available for only 7: the average size was 13 individuals, with a range of $2-29$. Average composition was $53 \%$ government, $13 \%$ industry, $8 \%$ academics, and $4 \%$ environmental group members; $22 \%$ of members were not identified. When a science advisory board was included in plan formation, the percentage of plans with at least one "inadequate" assessment was significantly lower than the proportion of plans with the same rating that did not employ a science advisory board (chi-square $=3.7, n=35, p<0.10$ ).

Species experts were consulted during development of 35 of the 43 HCPs reviewed, with developers of 6 plans not using these scientists and data not available for 2 plans. These consultations pertained to 87 of the 97 species examined, with experts not consulted for 7 species and data unavailable for 3 species. When biological "experts" on the species were consulted, the quality of plans was higher, in general, with a greater percentage of these plans having no “inadequate” or worse assessments (chi-square $=3, n=33, p<0.10$ ). [Figure 3]

\section{Discussion}

With the rapid proliferation of HCPs comes an increasing need to scrutinize the scientific merit of these documents, whether they are viewed primarily as compromise measures aimed at preventing species declines or as an alternative proactive strategy for protecting biodiversity on private lands. In either case, inherent within the HCP process is an assumption of flexibility that allows the plan preparers to address a suite of often conflicting biological, social, and economic objectives. Landowners and federal agencies (USFWS and NMFS) therefore have the ability to adapt the planning process to a particular situation, as long as the plan meets the basic requirements of the ESA: take does not significantly reduce species survival and recovery (Section 7), impact is mitigated to the maximum extent practicable (Section 10), and the best available science is used by the USFWS during consultation (Section 7). This flexibility, although perhaps the greatest strength of the HCP process, may also be its greatest weakness. Individual plans, through the agency consultation process, are required to include the "best" available data, but often such information is not accessible or is poor by scientific standards.

In general, we found that HCP preparers did a good job of using available, relevant information. For many categories of biological data found in both published and gray literature, the best available data were consistently used and cited. These results could indicate that either all appropriate information was used, available information was not used because it was not relevant to the HCP's conclusions, or information was simply not available and thus could not be incorporated into the document. For example, consider the Coast Range Conifers HCP, a permit to clear-cut old-growth forest inhabited by Northern Spotted Owls (Strix occidentalis caurina) and Marbled Murrelets in coastal Oregon. Information about habitat affiliations for the Spotted Owl was available and used well. Data on population genetics were available but not used; incorporation of these data, however, would not have affected the conclusions in the plan. Therefore, information that is available need not be included if it does not directly pertain to the specific issues being addressed. 
We found that for many species, however, there was little information available on basic biology and population status; in these cases it was not possible for the preparers of HCPs to obtain or use data that simply did not exist. This finding agrees with that of Wilcove et al. (1996), who cited USFWS statistics reporting that the status (increasing, declining, or stable) of 33\% of endangered or threatened species was unknown. Problems due to missing scientific information are compounded in each successive section of the planning process. Plans based on poorly understood species cannot accurately describe the current status of a species. A weak assessment of the current status of the population in the affected area will make it more difficult to estimate take, and will further make the task of calculating the effects of take more arduous. Thus, it is critical to ensure that basic biological information such as population size and distribution and habitat affiliations for each species be known or collected before project effects create significant changes to the local environment, especially for multiple projects with cumulative effects on a species. Further, assessments of project effects need to more clearly account for "uncertainty," be it disturbance, succession, environmental stochasticity, or natural and anthropogenic catastrophes. The importance of stochastic events in creating a lowered extinction threshold has been acknowledged (Man-gel \& Tier 1994), but it is often difficult to directly link these data to future population trends without a solid understanding of the current population's viability.

Qualitative assessments were utilized more often in plans because of a general paucity of quantitative data for many types of biological information. Although this type of analysis may often be appropriate, more rigorous analysis is required for some steps of the HCP process. Specifically, analyses of the future effects of a proposed action on a species' survival require quantitative estimates of the status and trends of the affected populations because of the unavoidable complexity of these predictions (Bingham \& Noon 1997). If such data are not currently available, the potential relationships between a population and the specific environmental factors can still be assessed through the use of appropriate statistical or modeling techniques (Noss et al. 1997). But the lack of quantitative data in many HCPs points to the need for a strong monitoring program that links ongoing data collections with the specific biological goals of the conservation plan (Shilling 1997).

Mitigation is one element of HCPs that would benefit from enhanced data collection and analysis to measure both the success of strategies applied to specific plans and for assessing general trends across plans. Mitigation strategies of known reliability were applied in HCPs more often than less documented ones, but, in general, many methods need to be more clearly and strongly justified. For example, two plans (Connel Gower and Coleman Company) involving the Utah prairie dog (Cynomys parvidens) relied on translocation as the primary form of mitigation, even though a previous study documented that 95\% of all previously translocated prairie dogs did not survive (McDonald 1993). In this HCP, the lack of prior translocation success was not described, perhaps because this mitigation strategy was supported in the recovery plan. In other cases, it is unclear whether mitigation will actually counter a project's effects, as Kareiva et al. (1998) report that the primary effects in $81 \%$ of plans are irreversible.

Given this uncertainty about the reliability of mitigation measures, it is disturbing that many of the proposed monitoring approaches are inadequate for determining mitigation success. Surprisingly, plans with the poorest estimates of predicted take had monitoring programs that failed to propose methods for collecting adequate data on the actual take of individuals. This suggests a need for increased application of adaptive management, which is broadly defined for HCPs as creating a data collection strategy that reduces the uncertainty surrounding the species conservation plan (USFWS \& NMFS 1996). One could excuse the poor quality of most 
monitoring programs by saying that painstakingly documenting a small effect is irrelevant, but in cases of multiple small plans there may be a large cumulative effect on a species. For example, the 94 plans written for the Goldencheeked Warbler (Dendroica chrysoparia) are likely to have small effects individually, but their combined effects could be significant, with a coordinated monitoring program across plans being necessary to ascertain the extent of take and subsequent effects on the species. In this case, adaptive management would not necessarily be applied within plans but rather across plans to increase the knowledge of general population trends, and possibly to test and perhaps replicate different mitigation strategies. Given the current requirements of HCPs, provisions appear to be inadequate for considering either the potential effect of cumulative activities on both federal and nonfederal lands or for implementing linked monitoring programs across plans.

One means of ensuring that current scientific information and approaches are used within the HCP process is through the increased involvement of independent scientists. When scientists, especially experts on the species covered by the plan, were consulted, adequate and even high-quality plans were often developed. Of course, merely consulting experts is not sufficient to increase the quality of the plan; the writers must incorporate the expert's recommendations. In the Balcones Canyonlands Conservation Plan, for example, the science advisory board recommended a 52,610-ha reserve designed to preserve habitat of the Golden-cheeked Warbler and Black-capped Vireo (Vireo atricapillus). But the final HCP aims to protect only 14,164 ha covering seven disjunct sites: the estimates of take include removal of $74 \%$ of the warbler habitat and $60 \%$ of the vireo habitat. Without critiquing the process by which these alternative mitigation strategies were developed, it appears that the science advisory board in this case was ineffective at developing an acceptable approach to protecting habitat for these species.

Although preparers of HCPs have the option to incorporate the recommendations of outside advisors, our results suggest that scientific rigor in HCPs increases with a higher degree of external scientific involvement. Two explanations can be proposed for this result: (1) plans with a strong existing scientific foundation tend to seek the advice of scientists, and (2) those plans that consult with scientists have better scientific information and analyses incorporated. At present, scientific input is not required under Section 10(a) of the ESA and is often lacking in conservation planning processes (Hosack et al. 1997), yet it seems both reasonable and feasible to include scientists in the HCP process (Meffe et al. 1998).

Because our results point to only a weak increase in scientific quality when science advisory boards were present during HCP development, it is unlikely that increased scientific involvement alone will be sufficient. Absent suitable and sufficient data, science advisory boards could have provided only qualitative advice based on their experience. If the availability and quality of scientific information were improved, then the expected benefits of scientific input could be more fully realized. Although scientific quality is not the only criterion by which HCPs may be judged, it is surely a key consideration in determining the long-term, cumulative effects of these projects on species survival and recovery.

Specifically, habitat conservation planning should place a stronger emphasis on the collection of data that is relevant to the species. Rather than using an ad hoc approach for monitoring or relying solely on the existing directives provided by recovery plans (Pyke et al. 1998), it would be helpful to have the USFWS and NMFS, along with scientific experts, create a list of prioritized biological questions to be addressed for each species. The conservation goals of each HCP could then be directly linked to these larger issues within the context of the specific local population and the project effects. By developing project-specific conservation goals that relate to these broader 
biological questions, several concurrent HCPs could address different but complementary questions, with knowledge gathered across plans being evaluated and incorporated by the agencies into a continually updated ecological model of the species. Furthermore, monitoring efforts should aim to test falsifiable hypotheses and, when possible, to provide confidence limits through sufficient sampling. Scientific committees, in cooperation with the agencies, could ensure that multiple plans for one species incorporated conservation goals specific to that species while also allowing for a diversity of approaches across plans. These oversight committees could review particular HCPs that had been implemented for a reasonable time period, with the purpose of evaluating the effectiveness of each plan. In particular, it would be worthwhile to investigate the causes of failure and to attribute them to a lack of data, poor interpretation or analysis, or simply unpredictable circumstances.

To enhance the scientific underpinnings of HCPs, we suggest that the following actions be incorporated into the planning process. First, existing scientific data should be used by agencies to develop a general strategy for an swering important questions on each species. Second, individual HCPs should include more independent scientists within the process to assist with developing and reviewing conservation strategies that aim to increase the cumulative knowledge about each species within the constraints and opportunities of the HCP projects. As our review points out, scientific information is generally used effectively, but more relevant data are clearly needed if we are to understand the short- and long-term prognosis of many species. Therefore, not only could habitat conservation plans potentially serve as a useful vehicle for gathering critical scientific data but, if adaptive management approaches are well designed and rigorously applied, it is possible that species conservation goals could be met through an integrated process of conservation planning on both public and private lands.

\section{Acknowledgments}

We would like to thank P. Kareiva and D. F. Doak for inspiration and guidance, the support staff at the National Center for Ecological Analysis and Synthesis for logistical assistance, and S. Happy for all his help. The U.S. Fish and Wildlife Service assisted with review of these data; M. J. Bean, D. F. Doak, F. C. James, C. McCulloch, L. S. Mills, and three anonymous reviewers provided helpful comments on the manuscript. Funding was provided by the American Institute of Biological Sciences, by the National Center for Ecological Analysis and Synthesis, and by a Graduate Research Traineeship (GER 9553614) from the National Science Foundation to E.K.H. and B.D.E.

\section{Literature Cited}

Bean, M. J., and D. S. Wilcove. 1997. The private land problem. Conservation Biology 11:1-2.

Bingham, B. B., and B. R. Noon. 1997. Mitigation of habitat "take": application to habitat conservation planning. Conservation Biology 11:127-139.

Hood, L. C. 1998. Frayed safety nets: conservation planning under the Endangered Species Act. Defenders of Wildlife, Washington, D.C.

Hosack, D., L. Hood, and M. Senatore. 1997. Expanding the participation of academic scientists in the HCP planning process. Endangered Species Update 14:60-62.

Kaiser, J. 1997. When a habitat is not a home. Science 276:1636-1638 
Kareiva, P., S. Andelman, D. Doak, B. Elderd, M. Groom, J. Hoekstra, L. Hood, F. James, J. Lamoreux, G. LeBuhn, C. McCulloch, J. Regetz, Savage, M. Ruckelshaus, D. Skelly, H. Wilbur, K. Zamudio, and NCEAS habitat conservation plan working group. 1998. Using science in habitat conservation plans. National Center for Ecological Analysis and Synthesis, Santa Barbara, California.

Mangel, M., and C. Tier. 1994. Four facts every conservation biologist should know about persistence. Ecology 75:607-614.

McDonald, K. P. 1993. Analysis of the Utah prairie dog recovery program, 1972-1992. Publication 93-16. Utah Division of Wildlife Resources, Cedar City, Utah.

Meffe, G. K., P. D. Boersma, D. D. Murphy, B. R. Noon, H. R. Pulliam,

L. E. Soulé, and D. M. Waller. 1998. Independent scientific review in natural resource management. Conservation Biology 12:268-270.

Noss, R. F., M. A. O’Connell, and D. D. Murphy. 1997. The science of conservation planning: habitat conservation under the Endangered Species Act. Island Press, Washington, D.C.

Pyke, C. R., B. Bierwagen, and N. Goldstein. 1998. Strange bedfellows: observations on the current relationship between recovery plans and habitat conservation planning. Endangered Species Update 15: 97-104.

San Bruno Mountain Habitat Conservation Plan, San Mateo County, California. 1982. San Bruno Mountain Habitat Conservation Plan Steering Committee, San Mateo, California.

Savage, L. T. 1998. Innovative national graduate student seminar ana-

lyzes habitat conservation plans. Integrative Biology 1:45-48. Shilling, F. 1997. Do habitat conservation plans protect endangered

species? Science 276:1662-1663. U.S. Fish and Wildlife Service (USFWS) and National Marine Fisheries Service (NMFS). 1994. Endangered and threatened wildlife and plants: notice of interagency cooperative policy on information standards under the Endangered Species Act. Federal Register 59:34271.

U.S. Fish and Wildlife Service (USFWS) and National Marine Fisheries Service (NMFS). 1996. Habitat conservation planning handbook. U.S. Department of the Interior, Washington, D.C.

U.S. Fish and Wildlife Service (USFWS) and National Marine Fisheries Service (NMFS). 1999. Notice of availability of a draft addendum to the final handbook for habitat conservation planning and incidental take permitting process. Federal Register 64:11485-11490.

Wilcove, D. S., M. J. Bean, R. Bonnie, and M. McMillan. 1996. Rebuilding the ark: toward a more effective Endangered Species Act for private land. Environmental Defense Fund, Washington, D.C. 


\begin{tabular}{|c|c|c|c|}
\hline \multirow[b]{2}{*}{ Common name } & \multirow[b]{2}{*}{ Scientific name } & \multicolumn{2}{|c|}{$\begin{array}{c}\text { Number of incidental } \\
\text { take permits }\end{array}$} \\
\hline & & all plans & $\begin{array}{l}\text { analyzed } \\
\text { plans }\end{array}$ \\
\hline Golden-cheeked Warbler & Dendroica chrysoparia & 94 & 4 \\
\hline Florida Scrub Jay & Aphelocoma coerulescens & 14 & 4 \\
\hline Alabama beach mouse & Peromyscus polionotus ammobates & 11 & 4 \\
\hline Red-cockaded Woodpecker & Picoides borealis & 9 & 3 \\
\hline Desert tortoise & Gopberus agassizit & 8 & 2 \\
\hline San Joaquin kit fox & Vulpes macrotts mutica & 8 & 3 \\
\hline Northern Spotted Owl & Strix occidentalis caurina & 8 & 4 \\
\hline Marbled Murrelet & Bracbyrampbus marmoratus & 7 & 4 \\
\hline California Gnatcatcher & Polioptila californica californica & 7 & 3 \\
\hline Blunt-nosed leopard lizard & Gambelia silus & 7 & 2 \\
\hline Bald Eagle & Haliaeetus leucocepbalus & 6 & 3 \\
\hline Stephen's kangaroo rat & Dipodomys stepbensi & 6 & 2 \\
\hline Utah prairie dog & Cynomys parvidens & 5 & 2 \\
\hline Peregrine Falcon & Falco peregrinus & 5 & 2 \\
\hline
\end{tabular}

*Data are for plans approved before September 1997 (195 total and 30 species in analyzed plans; some plans cover more than one species and thus the total does not add to 30 ).

Table 1. The 14 most common threatened and endangered species in habitat conservation plans and the number of incidental take permits issued for each.*

\begin{tabular}{|c|c|c|c|c|c|}
\hline Category and informaton & Known & Unknown & $\begin{array}{c}\text { Quantitative } \\
\text { estimate }\end{array}$ & $\begin{array}{l}\text { Qualitative } \\
\text { estimate only }\end{array}$ & $\begin{array}{c}\text { Unable to } \\
\text { answer }\end{array}$ \\
\hline \multicolumn{6}{|l|}{ Life history } \\
\hline lifespan & 31 & 17 & & & 19 \\
\hline ro (reproductive rate) & 13 & 34 & & & 20 \\
\hline clutch (or litter) size & 43 & 5 & & & 19 \\
\hline any one of the above & 45 & 5 & & & 17 \\
\hline \multicolumn{6}{|l|}{ Local trends } \\
\hline population size & & 29 & 5 & 30 & 3 \\
\hline habitat quantity & & 11 & 3 & 47 & 6 \\
\hline range change & & 21 & 2 & 34 & 10 \\
\hline any one of the above & & 10 & 6 & 50 & 1 \\
\hline \multicolumn{6}{|l|}{ Global trends } \\
\hline population size & & 24 & 5 & 36 & 2 \\
\hline habitat quantity & & 12 & 3 & 46 & 6 \\
\hline range change & & 16 & 2 & 43 & 6 \\
\hline any one of the above & & 9 & 6 & 51 & 1 \\
\hline
\end{tabular}

"Unknown" indicates that data did not exist or could not be determined; "unable to answer" indicates that the question was not applicable; $\mathrm{n}=67$ species covered by at least one $\mathrm{HCP}$ we reviewed.

Table 2. Number of examined species in habitat conservation plans for which information was available in the published or gray literature for three categories: life history, local trends, and global trends.* 


\begin{tabular}{lcccc} 
& \multicolumn{4}{c}{$\begin{array}{c}\text { Species witb little or no information } \\
\text { missing (\%) }\end{array}$} \\
\cline { 2 - 5 } Category of data & status & take & impact & mitigation \\
\hline Population size & 92 & 95 & 90 & $\mathbf{8 2}$ \\
Population trends & 93 & 91 & 92 & 92 \\
Habitat amount & $\mathbf{8 9}$ & $\mathbf{8 4}$ & 91 & 88 \\
Habitat quality & $\mathbf{8 5}$ & $\mathbf{8 2}$ & $\mathbf{8 9}$ & $\mathbf{8 2}$ \\
\hline
\end{tabular}

Table 3. Percentage of examined species for which little or no information was missing in the habitat conservation plan compared with available scientific literature for four categories of commonly used data in each of four steps of analysis (status, take, impact, mitigation) within 43 examined plans.

\begin{tabular}{lccccc} 
Nature of missing information & Status & Take & Impact & Mitigation & $\begin{array}{c}\text { Across all } \\
\text { sections }\end{array}$ \\
\hline Nothing significant missing & 3 & 11 & 5 & 1 & 0 \\
Not important for conclusions & 14 & 13 & 15 & 11 & 11 \\
Would have changed conclusions qualitatively & 13 & 13 & 15 & 17 & 15 \\
Starkly necessary information missing & 13 & 6 & 7 & 14 & 17 \\
\hline
\end{tabular}

Table 4. Number of plans for which at least some available data were missing for a minimum of one species within each of four steps of analysis (status, take, impact, mitigation) in a habitat conservation plan $(n=43)$.

\begin{tabular}{|c|c|c|c|c|}
\hline \multirow[b]{2}{*}{ Category of information } & \multicolumn{4}{|c|}{ No. of plans with important missing information } \\
\hline & status & take* & impact & mitigation \\
\hline Habitat quantity and quality & 5 & 8 & 5 & 10 \\
\hline Population numbers & 3 & 8 & 1 & 4 \\
\hline Demographic rates and trends & 6 & 4 & 6 & 5 \\
\hline Metapopulations & 4 & 5 & 2 & 4 \\
\hline Genetics & 4 & na & 2 & 4 \\
\hline Community interactions & 2 & 1 & 3 & 7 \\
\hline External environment & 3 & 2 & 5 & 1 \\
\hline Stochastic processes & 3 & na & 11 & 15 \\
\hline Cumulative or interaction effects & 3 & na & 1 & 3 \\
\hline
\end{tabular}

"na, not available.

Table 5. Number of habitat conservation plans for which available scientific information, by category, would have changed the conclusions at least "qualitatively" within each of four steps (status, take, impact, mitigation) of analysis $(n=43)$. 


\begin{tabular}{lrrrr}
\hline Data and analysts used & Status & Take & Impact & Mitigation \\
\hline Expert opinion & 2 & 4 & 2 & 6 \\
Qualitative data or quantitative data, but limited or poor analysis & 37 & 40 & 38 & 35 \\
Quantitative data, with clear and relevant analysis & 48 & 40 & 34 & 35 \\
Quantitative data, with good modeling of processes to extrapolate into the future & 8 & 2 & 7 & 7 \\
No assessment & 2 & 11 & 16 & 14 \\
\hline
\end{tabular}

Table 6. Number of examined species that utilized each category of data or type of analysis within each assessment step (status, take, impact, mitigation) of a habitat conservation plan (excluding monitoring) $\left(n_{-} 97\right)$.

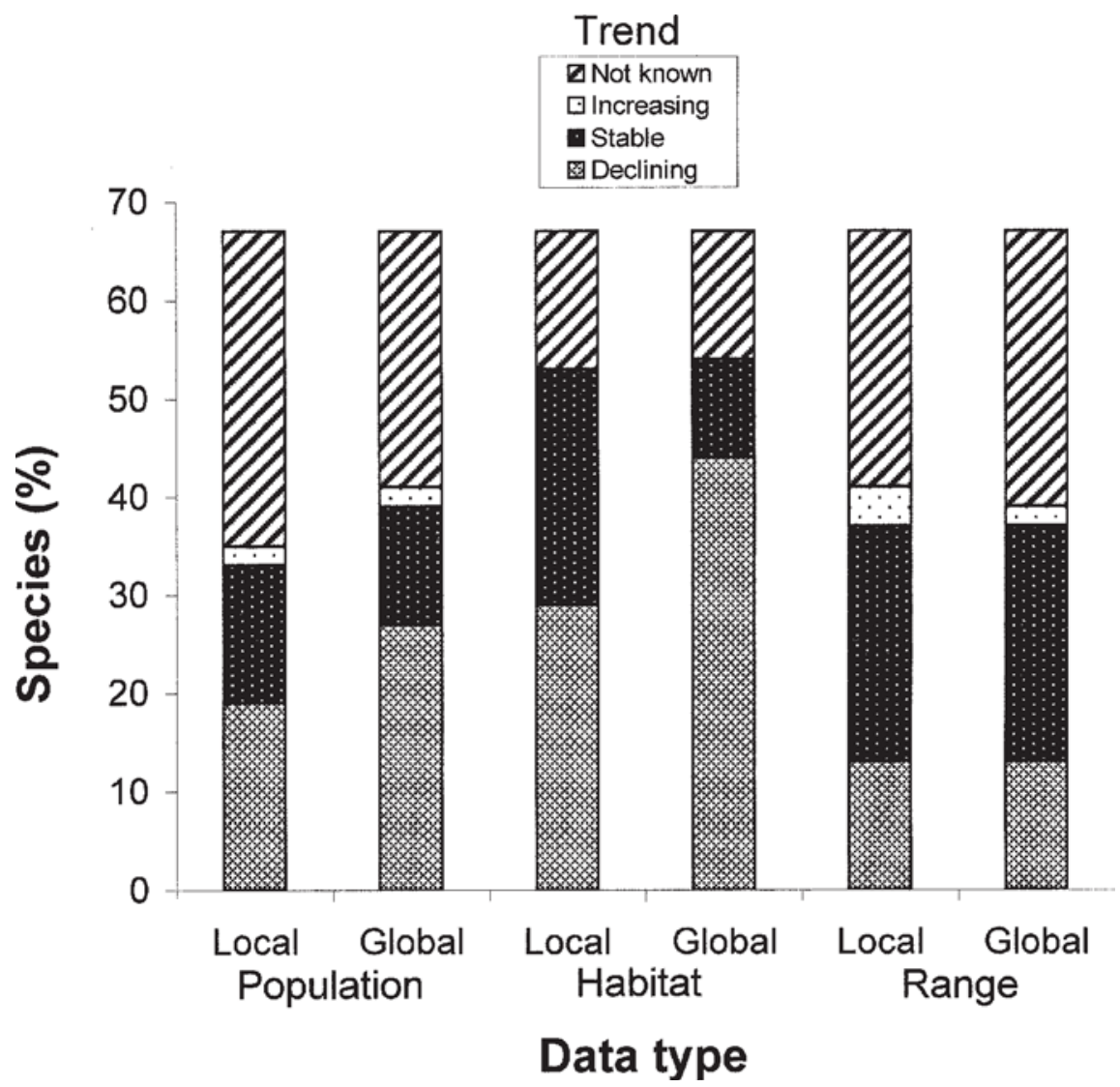

Figure 1. Proportion of species reporting a trend of either increasing, stable, or decreasing for local and global data on population, habitat, and range. "Not known" includes answers for which data did not exist or could not be determined. The total excludes those answers that were not applicable and therefore does not add to $100 \%$. 


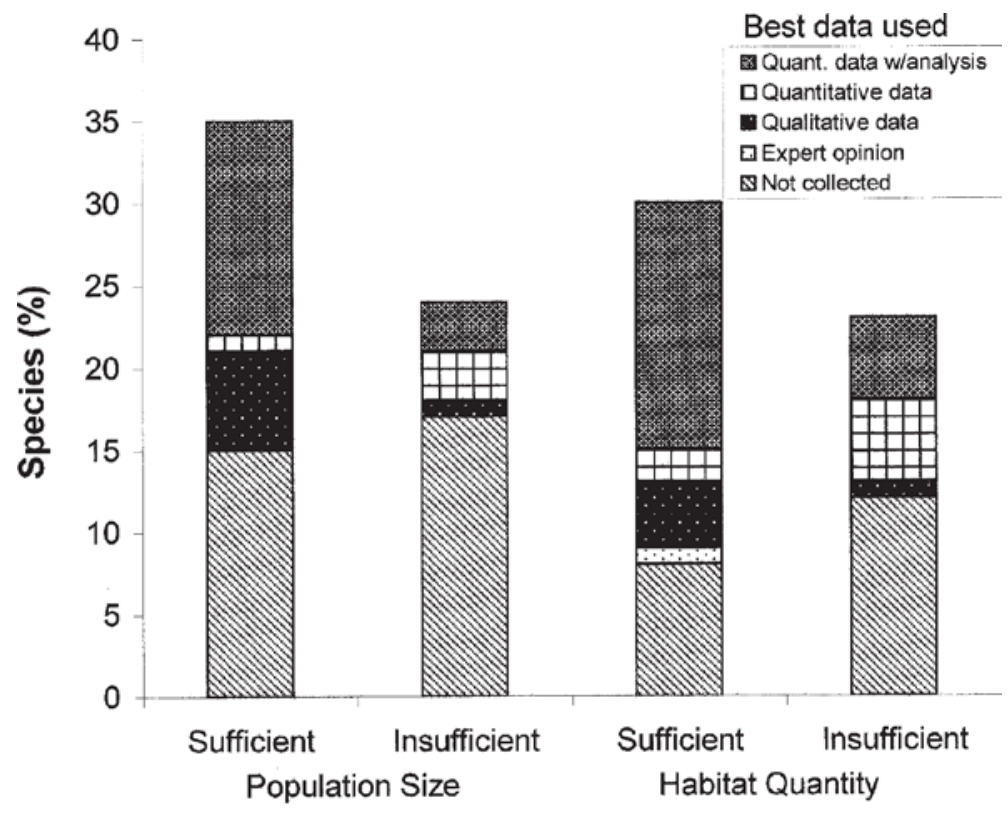

Data category/sufficiency of monitoring

Figure 2. Proportion of species with monitoring programs sufficient or insufficient to determine mitigation success for two categories of information often collected, population size and amount of habitat. Each category of information is further subdivided by the type of data collected, with the last two categories merged (see Methods). 


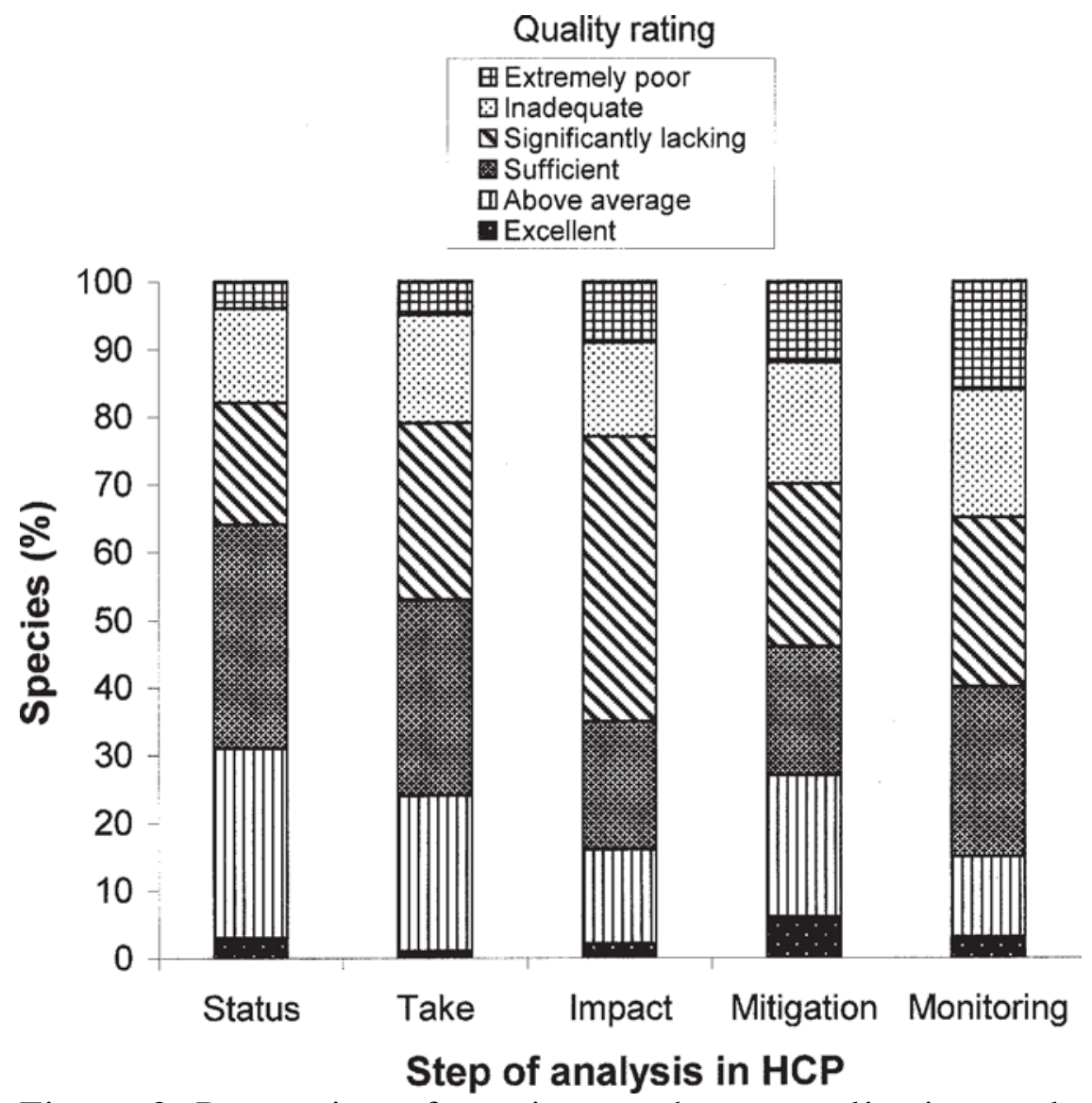

Figure 3. Proportion of species rated on a qualitative scale from 1, excellent, to 6, extremely poor, within each step of analysis (e.g., status, take) across the 43 examined habitat conservation plans. 


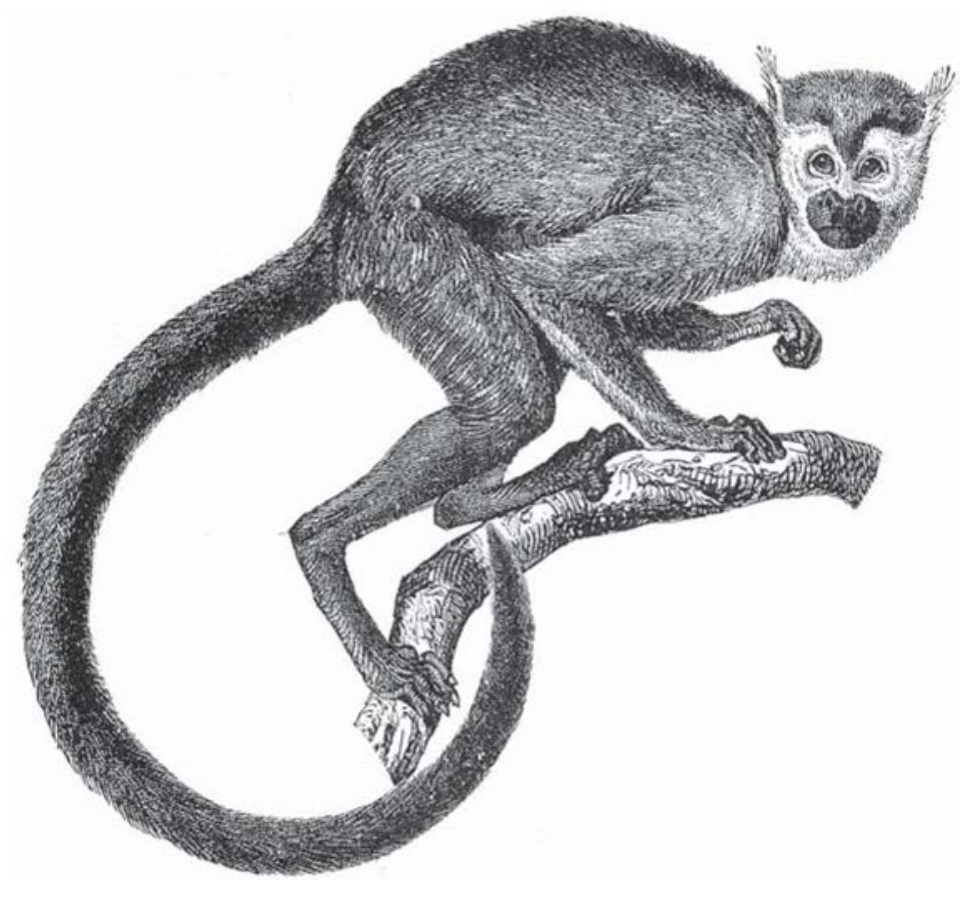

